DOI: 10.14483/udistrital.jour.infimg.2014.2.a13

\title{
Literatura infantil en la contemporaneidad: el mundo real de los niños*
}

\section{Children's Literature in Contemporary Times: The Real World of Children}

\author{
Sandra Milena Rojas Camargo ${ }^{* *}$ Sandra Hortencia Saboya Alemán ${ }^{* * *}$
}

Para citar este artículo: Rojas, S. M.; Saboya, S. H. (2014). Literatura infantil en la contemporaneidad: el mundo real de los niños. Infancias Imágenes, 13(2), 152-158

Recibido: 16-septiembre-2014 / Aprobado: 25-noviembre-2014

\section{Resumen}

El artículo busca dar a conocer algunos aportes de teóricos en literatura infantil en la contemporaneidad, tópico de vital importancia para educadores, estudiantes y todo aquel interesado por el mundo de las letras. En el texto se da respuesta a los siguientes cuestionamientos: ¿Qué se entiende por literatura infantil? ¿Cuáles son los temas que aborda? ¿Qué significa ser lector y escritor de literatura infantil? ¿Cómo se caracteriza el libro álbum? Este texto muestra cómo el concepto de literatura infantil en la contemporaneidad está en construcción, teniendo como base los cambios de cosmovisión respecto a la manera como se concibe la infancia.

Palabras clave: lectura, escritura, libro álbum

\begin{abstract}
The article seeks to present some contributions of theorists in children's literature in the contemporary times, topic of vital importance for educators, students, and anyone interested in the literary world. The text responds to the following questions: What is understood by children's literature? What are the subjects addressed? What does it mean to be a reader and a writer of children's literature? How is the book album characterized? This text shows how the concept of children's literature in the contemporary times is under construction, on the basis of worldview changes as to how childhood is conceived.
\end{abstract}

Keywords: reading, writing, book album

* Este artículo surge como resultado de la investigación en desarrollo (inició en agosto de 2013) "Concepciones de literatura infantil en la contemporaneidad y su incidencia en la formación de lectores y escritores literarios en educación inicial pública en Bogotá".

** Licenciada en Educación Básica con énfasis en Humanidades y Lengua Castellana, docente de primaria, Secretaría de Educación del Distrito de Bogotá. Correo electrónico: rocasam@hotmail.com

*** Licenciada en Educación Básica con énfasis en Humanidades y Lengua Castellana, docente de primaria, Secretaría de Educación del Distrito de Bogotá. Correo electrónico: sandyalem@hotmail.com 


\section{INTRODUCCIÓN}

Este artículo da cuenta de los elementos que necesariamente emergen en un contexto contemporáneo en cuanto al arte de las letras destinado a un público infantil. Es así como el texto empieza exponiendo la relación de lo clásico con lo contemporáneo en términos de literatura infantil; y a continuación presenta las características que podrían definir al lector, escritor y obra de la literatura dirigida a un público que se encuentra en su infancia. Hay que aclarar que el concepto de literatura infantil en la contemporaneidad (LIC) estudiado en este texto se aleja de las nociones básicas en las que esta es limitada solamente a la enseñanza de la lectura y la escritura (procesos de lectura y escritura entendidos como decodificación y codificación, y no como acto creador y canal de experiencia estética).

Discutir sobre la literatura infantil o de una literatura cuyo destino es el público que se encuentra en su infancia es un fenómeno que se da en el mundo moderno. Esta denominación emerge en el siglo XVIII, época en que se crearon libros dirigidos para la infancia, los cuales fueron considerados en primer lugar como herramienta educativa y luego como entretenimiento, lo cual fue resultado de la importancia que para entonces empezó a darse a la concepción de infancia, entendida como aquella etapa de la vida del ser humano diferente a la vida adulta.

El concepto de LIC está en construcción. Incluye todas las variables en torno a las consideraciones sobre lo que significa ser niño o estar en la etapa llamada infancia. Significado determinado por el contexto histórico, social y cultural en el cual se consolida: por ejemplo, cuando se habla de infancia en un contexto social indígena, no es igual a mencionarla en un contexto social de ciudad, que tendría sus variaciones frente al rural. Las condiciones y nociones sobre infancia incluso presentan variaciones de un estrato socioeconómico a otro; así mismo, podrían variar entre países de acuerdo con la cultura.
Al referirnos a la literatura infantil se hace alusión en sus orígenes a los cuentos populares o clásicos, los cuales han sufrido desde su aparición transformaciones que obedecen a los cambios de la sociedad con respecto a su manera de ver la infancia. Los orígenes tanto del cuento popular o clásico como del actual o contemporáneo han dado lugar a comparaciones entorno a su surgimiento:

El cuento clásico o tradicional no fue creado para niños. Es de raíces populares y solo su esquematismo, su didactismo patente, su ingenuidad y primitivismo y, en algunas ocasiones las adaptaciones más o menos afortunadas, han hecho que con el tiempo se haya destinado preferentemente al niño, llegando a constituirse en arquetipo del cuento para niños. El cuento actual, por el contrario, nace predestinado para el niño. Mientras el primero ha sido sometido a un largo proceso colectivo de decantación y selección que ha resistido el paso del tiempo, el segundo es fruto directo de un autor determinado y concreto, a veces con su finalidad también concreta y determinada (Cervera, 1988, p.168).

Colomer (1999) sostiene que en la actualidad se ha presentado una adaptación de los viejos cuentos a los nuevos valores morales; y en versiones actuales, además de cierto grado de violencia, se puede ver el reflejo de preocupaciones propias de la sociedad de hoy: la mujer, la ecología o el cambio de perspectiva cultural, en ocasiones surge un juego amoral, ya que los trasgresores no son castigados o el cuento se convierte en un simple juego de humor metaliterario. La nueva lectura o producción de literatura infantil contemporánea no se propone olvidar o sustituir la antigua, sino que exige que el lector mantenga la versión tradicional y así poder hallar la diferencia con la moderna, para ver la distancia y el juego intertextual entre ambas. Aunque se mantienen en ocasiones las historias de cuentos populares, estas se presentan al lector de manera diferente, haciendo uso del poder de la imagen y juegos intertextuales. 


\section{La complejidad de la vida en los relatos infantiles}

En las definiciones de la LIC es necesario tener en cuenta aquellas que consideran el papel del adulto como escritor, el niño como lector (los intereses que él pueda tener) y la obra literaria, la cual hace uso de lo lúdico y creador del lenguaje. Una de las definiciones que tiene en cuenta estos tres aspectos la ofrece Graciela Perriconi:

La literatura infantil es un acto de comunicación, de carácter estético entre un receptor niño y un emisor adulto, que tiene como objetivo la sensibilización del primero y como medio la capacidad creadora y lúdica del lenguaje, y debe responder a las exigencias y necesidades de los lectores... lo artístico en la literatura infantil radica en la creatividad y en el aspecto simbólico, representativo y traslativo del mensaje (1983, p.7).

La LIC ilustra los cambios de cosmovisión que las sociedades posmodernas han traído consigo. Fenómenos como la globalización han hecho que este tipo de literatura no tenga fronteras y fácilmente desaparezcan limitaciones referidas a la lengua original en la que se produce el cuento o narración. Las bibliotecas a las que tienen acceso los estudiantes y demás público interesado en este tipo de literatura están Ilenas de autores extranjeros, que cuentan historias sobre situaciones humanas que se dan en cualquier lugar del mundo.

Empiezan a vislumbrase en la literatura infantil a su vez juegos de metaficción. Una historia que evidencia la inmersión de la metaficción es Voces en el parque, de Anthony Browne (2000), obra literaria que cuenta las razones para ir al parque y la experiencia que allí se vive, desde diferentes voces, la de la mamá y su hijo; la del vagabundo y su hija.

La LIC es el resultado de los cambios que a diario ocurren en la sociedad en términos de ideología, idiosincrasia, identificación cultural y reivindicación de género. Se empieza a dar protagonismo al conflicto o diferencia como parte esencial en las relaciones humanas.

Las sociedades posmodernas han sufrido cambios en cómo se valora el mundo y las relaciones interpersonales e intrapersonales. Esto trae consigo una nueva cultura, que no es otra que la de lo efímero y transitorio, que transforma las normas e impone unos valores materialistas, económicos y competitivos, dando la noción de que es más importante "tener" que "ser". En ocasiones, convierte al ser humano en un ser xenófobo, insolidario y por momentos incomprensivo frente a la desigualdad social que ha generado este tipo de manera de concebir el mundo. Estas nuevas cosmovisiones han incursionado en la literatura infantil de nuestra contemporaneidad y han evidenciado nuevos temas que responden a la complejidad de la vida.

En la LIC hay una invitación intrínseca al lector en torno al conflicto como parte inevitable en la vida del ser humano. Muerte, locura, enfermedad, minusvalía, incomunicación, pobreza, clases sociales, así como las formas de enfrentar el dolor, son temas que comienzan a tener eco en las creaciones literarias infantiles actuales. Un ejemplo relacionado con la desigualdad social es el libro ;Mi papá no apesta!, de Andrée Poulin (2011), en el cual Margarita, una niña de aproximadamente 8 años, narra a sus compañeros que su papá trabaja recogiendo basuras, ante lo cual cual sus compañeros de clase se ríen; entonces comienza la historia alrededor de un oficio que es necesario para el buen funcionamiento de la sociedad.

En la LIC, la fantasía puede cuestionar la realidad. El libro Camino a casa, de Jairo Buitrago (2008), muestra cómo una niña de condiciones socioeconómicas adversas le pide a un león que la acompañe a casa, lo cual el animal hace gustosamente mientras le muestra situaciones de finales de la Segunda Guerra Mundial.

Otros temas que se involucran a la actual literatura infantil son los cambios sociológicos de la familia: "Desde que empezaron a publicarse libros para niños la familia ha sido un escenario habitual en el que situar las aventuras de los protagonistas 
infantiles" (Colomer, 1999, p.116). Por mucho tiempo, la estructura familiar se establecía en torno a la delegación de roles (el padre salía a trabajar y la madre se quedaba en casa). Las sociedades actuales demandan que en los hogares todos los adultos salgan a trabajar y en muchos hogares la mujer, aparte de salir a trabajar, debe llevar también la carga de los quehaceres domésticos. Anthony Browne (2002), en su cuento El libro de los cerdos, logra de una manera metafórica llevar este conflicto a la literatura infantil, mostrándolo de manera divertida, pero sin dejar de fondo la denuncia social que no es otra que la recarga laboral de la mujer.

La crítica a las sociedades posindustriales y la multiculturalidad se hacen presentes en la LIC: "Desde la Segunda Guerra Mundial, fomentar el conocimiento y el respeto por las demás razas y culturas ha sido un valor primordial de la literatura infantil y juvenil" (Colomer, 1999, p.121). En textos como Choco encuentra una mamá, de Keiko Kasza (1992), esto queda en evidencia. Esta obra narra la historia de un pájaro huérfano que sale en busca de una mamá, pero se encuentra con el desprecio de varios de los animales que le aseguran que no podría ser su hijo porque hay diferencias muy marcadas, hasta que una osa decide adoptarlo pese a lo diferentes que son. De esta misma manera, el cuento Niña bonita, de Ana María Machado (2001), muestra cómo un conejito blanco pasa por una serie de obstáculos para poder ser negro como su niña bonita, teniendo de manera constante y repetitiva en el cuento la pregunta "¿cuál es tu secreto para ser tan negrita?". Hasta que se descubre que el secreto reside en su color de piel.

Un componente que empieza a aparecer en la LIC es la llamada narración psicológica: "Los conflictos psicológicos tienen una presencia abrumadora en la literatura infantil y juvenil actual... abundan los problemas derivados de las crisis madurativas que se suponen propias de estas edades" (Colomer, 1999, p.126). Una creación literaria que ejemplifica este tipo de característica es el cuento de Anthony Browne (2011) Ilamado Willy el Mago, que hace alusión a un niño gorila en condiciones socioeconómicas difíciles, quien anhela hacer parte de un equipo de fútbol con integrantes mayores que él, pero no es tenido en cuenta. De repente, el personaje tiene un amigo imaginario que le obsequia unos guayos que lo hacen famoso. Este texto incursiona así una etapa de desarrollo psicológico en el cual los niños pueden llegar a tener un amigo imaginario.

Se puede ver cómo el telón que separaba la literatura para adultos de la literatura infantil se ha venido corriendo, haciendo que sea una limitante inestable. Inclusive, por ejemplo, muchos de los libros para niño hoy manejan un discurso ambientalista y de denuncia de una posible destrucción del planeta. En la obra El canto de las ballenas, de Dyan Sheldon (2003), se narra desde un punto del tiempo en el que ya no existen las ballenas y se dan las razones de su desaparición, lo que vuelve mágico poder escucharlas.

\section{El arte de escribir letras para niños}

La LIC no siempre se crea para un público infantil, en ocasiones son otros factores los que indicen en el cambio de receptores para los que inicialmente fue escrita. En varias oportunidades puede llegar a ser el proceso de mercado. Ema Wolf, escritora de literatura infantil (citada por Acosta, 2011) dice que cuando escribe no lo hace pensando en una edad determinada, ya que serán sus lectores quienes escogerán sus textos, a partir de la complejidad que presenten, y agrega que al escribirlos no se siente como niña, sino como adulta. Esta literatura escrita no necesariamente pensada en un público infantil y que luego, por diferentes razones, llega a los gustos y las manos de los niños es lo que Beatriz Robledo (citada por Acosta, 2011) Ilama la literatura ganada: "Aquella que no es escrita para niños pero ha sido destinada o adquirida para ellos por medios como la escuela, el hogar, los proyectos editoriales y la propia historia de la lectura" (Acosta, 2011, p.86). 
Esto indica que hay una influencia externa alrededor del escritor, la cual incide en su consolidación. Una de las influencias más marcadas es el papel de la edición. Acosta (2011) vislumbra cómo al hablar de un escritor de literatura infantil se presentan varias aristas importantes: en primer lugar, se debería hablar de un escritor-escritor quien es motivado por sus propios procesos de expresión, como aquel que primero es lector y posteriormente es creador de la obra. Luego aparece en escena el escritor-autor, que es aquel que lo hace por su interés de comunicación, es decir, se debe a sus lectores; finalmente, al mencionar un escritor de literatura infantil, es necesario traer a colación el autor o escritor que no solo está comprometido con la escritura sino con los procesos de ilustración y edición. Para Lluch (2004, p.46), un buen editor es aquel que opera de manera concéntrica en tres ámbitos, es decir, aquel que tiene una notable sensibilidad intelectual, artística y comercial. No es nada extraño encontrar en los libros de esta literatura (libro álbum) mención al escritor, sino al ilustrador que lo acompaña. Además, no se desconoce el papel que el traductor puede llegar a jugar en la construcción del sentido de la historia.

Este escritor de LIC, desde cualquiera de las categorías anteriores, enfrenta interrogantes antes de cumplir su papel. Marina Colasanti (citada por Acosta, 2011) señala que el autor se enfrenta a algunos cuestionamientos frente a la pregunta " $i y$ qué vas a escribir?":

¡Y lo niños son muy delicados! ¡Les queda todo grabado en el inconsciente! ¡Cualquier palabra puede ser fatal! ¡Corres el riesgo de trasmitirles ideas equivocadas! ¡Corres el riesgo de no trasmitirles ninguna idea! Si intentas enseñarles algo harás literatura didáctica — ieso no es bueno! Si no quieres enseñarles nada probablemente harás literatura alienada- ¡eso es pésimo! Y más, retumbando la pregunta con estrepito de trueno, ¿qué derecho tienes tú, qué sabiduría, qué madurez, para escribir para niños? (Acosta, 2011, p.88).
Entonces, desde este punto de vista siempre habrá autores que no quieran despojarse de su condición de adulto al escribir literatura infantil y autores que, en cambio, quieran volver a su papel de niño. Cualquiera que sea el caso, en determinado momento todos se cuestionan sobre el concepto de infancia, el cual está siempre mediado por las condiciones socioculturales en las cuales se vive. "El autor contemporáneo se preocupa, por ejemplo, por la edad cronológica de su lector mediado regularmente por proyectos editoriales, por aquello que algunos han denominado gráficamente 'literatura por tallas'" (Acosta, 2011, p.93).

Otra arista que hay que tener en cuenta en la configuración del escritor de la LIC en la actualidad es el medio por el cual da a conocer su obra. Las nuevas tecnologías empiezan a evidenciar la variedad de medios a través de los cuales llega este tipo de literatura a los niños, al punto que "ya se plantea la tensión permanente entre los nuevos medios y la lectura en el formato del libro y las diversas perspectivas en las que se señala la necesidad de la alfabetización y la capacidad de lectura" (Acosta, 2011, p.102).

\section{EI lector literario y sus posibilidades de sentido}

Definir a un lector de LIC demanda concebirlo como aquel que desempeña un rol activo en el momento de acercarse y conocer la obra. El lector de LIC es aquel que, en términos de Acosta (2011), está mediado por un animador, es decir, es muy probable que en la mayoría de encuentros esté orientado por un adulto, ya sea en su rol de padre, maestro, guía de algún tipo de institución de lectura o de aquellos programas que ofrecen al niño los libros que debe leer. Este mediador es quien lo motiva y contesta la pregunta ¿qué leer? Es así como el lector literario encuentra que la literatura infantil es determinada en su mayoría por otro (generalmente adulto) a partir de unos rangos de edad en los que ha sido separada este tipo de literatura. 
En la mayoría de los casos, el libro infantil y juvenil no se dirige a un único receptor; por eso hablamos de un doble lector. El primero es el padre o el maestro: no son los lectores directos de estos libros, sino unos intermediarios encargados de su compra o recomendación a los que los leerán; y el segundo ya es el niño o el adolescente, el lector real (Lluch, 2004, p.46).

Atendiendo a la obra como tal, se presentan unos requerimientos para aquellos lectores que se adentran en la lectura de la obra de la LIC. Acosta destaca "exigencias en el lector y saberes especiales, que van desde la atención a la construcción narrativa, como a saberes específicos alrededor de la gramática de la imagen" (2011, p.114).

Al enfrentarse a la obra, el lector comienza a desempeñar un rol esencial:

Ocupa un papel fundamental en el proceso de la lectura, el lector con todo su bagaje, sus esquemas previos, su conocimiento, su visión de mundo, su experiencia, su historia personal y el texto, sujeto de lenguaje, Ileno de posibilidades de sentido, texto que calla y oculta, que sugiere y expresa, que narra, explica, o enumera (Robledo, 2011, p.72).

Pensar en las características propias de un lector de LIC, como uno de los objetivos primordiales en el camino estudiantil, implica la revisión de aquellas prácticas que se presentan en el aula en el acercamiento a la lectura de este tipo de literatura, así como entender que el mediador juega un rol fundamental en su proceso de construcción.

\section{La obra de LIC: el libro álbum}

Referirse a la LIC es hablar también de ilustración, por eso no se podría hablar de ella sin hacer alusión al libro álbum, característico en este tipo de literatura y que ha logrado acoger a numerosos lectores, así como a sus críticos y a todos aquellos que intervienen en su consolidación. Este ha sido el producto de una evolución tecnológica que se ha presentado en la posmodernidad. En el Ilamado libro álbum se encuentra una conexión entre imágenes y texto, con un lenguaje híbrido que empieza a ser objeto de estudio por la interrelación e interdependencia de estas dos formas de lenguaje.

Hanán comenta al respecto: "El libro álbum auténtico se sostiene en esta interdependencia. Las imágenes no pueden ser entendidas sin los textos y los textos pierden sentido si se leen separadamente" (2007, p.95). Por ejemplo, en el libro Los colores de Elmer, de David McKee (1994), se evidencia esta interdependencia. La historia es sobre el elefante Elmer y su amor por los colores, historia que sería imposible de reconstruir si a los textos se les quitan las imágenes y viceversa.

En el libro álbum la imagen se muestra como simbolismo cargado de sentido cuya función no se reduce a la simple ilustración, sino que desarrolla la capacidad creativa del lector que la enfrenta.

\section{REFERENCIAS}

Acosta, C. (Coord.) (2011). Pensar la literatura infantil. Interpretación a varias voces. Bogotá: Universidad Nacional de Colombia.

Buitrago, J. (2008). Camino a casa. Ilustrado por Rafael Yockteng. México: Fondo de Cultura Económica.

Browne, A. (2000). Voces en el parque. Madrid: Fondo de Cultura Económica de España.

Browne, A. (2002). El libro de los cerdos. Madrid: Fondo de Cultura Económica de España.

Browne, A. (2011). Willy el Mago. Madrid: Fondo de Cultura Económica de España.

Cervera, J. (1988). La literatura infantil en la educación básica. Madrid: Cincel.

Colomer, T. (1999). Introducción a la literatura infantil y juvenil. Madrid: Síntesis.

Hanán, F. (2007). Leer y mirar el libro álbum: ¿Un género en construcción? Bogotá: Norma.

Kasza, K. (1992). Choco encuentra una mamá. Bogotá: Norma.

Lluch, G. (2004). Cómo analizamos relatos infantiles y juveniles. Bogotá: Norma. 
Machado, A. (2001). Niña bonita. Ilustrado por Rosana Faria. Caracas: Ekaré.

McKee, D. (1994). Los colores de Elmer. México: Fondo de Cultura Económica.

Perriconi, G. (1983). El libro infantil: cuatro propuestas críticas. Buenos Aires: Librería El Ateneo.
Poulin, A. (2011). ¡Mi papá no apesta! Ilustrado por: Jean Morin. Zapopan: Petra.

Robledo, B. (2011). La literatura como espacio de comunicación y convivencia. Buenos Aires: Lugar Editorial.

Sheldon, D. (2003). El canto de las ballenas. México: Ekaré.

\section{(c) $(1)(8)$}

